\title{
Fabrication and in vitro Evaluation of 4-HIA Encapsulated PLGA Nanoparticles on PCI2 Cells
}

\author{
Tekupalli Ravikiran, (D) \\ Santosh Anand, (iD) ${ }^{2}$ \\ Mohammad Azam Ansari, (D) ${ }^{3}$ \\ Mohammad N Alomary, (iD) \\ Sami AIYahya, ${ }^{4}$ \\ Sowbhagya Ramachandregowda,' \\ Saad Alghamdi, (D) 5 \\ Anupama Sindhghatta Kariyappa,' \\ Bhagyalakshmi Dundaiah,' \\ Mamatha Madhugiri Gopinath,' \\ Sumreen Sultana, (ID) \\ Shital Manohar Punekar, (D) \\ Thimappa Ramachandrappa \\ Lakshmeesha' \\ 'Department of Biotechnology, Bangalore \\ University, Bangalore, India; ${ }^{2}$ Department \\ of Biotechnology, School of Applied \\ Sciences, Reva University, Bengaluru, \\ India; ${ }^{3}$ Department of Epidemic Disease \\ Research, Institutes for Research and \\ Medical Consultations (IRMC), Imam \\ Abdulrahman Bin Faisal University, \\ Dammam, 3I44I, Saudi Arabia; ${ }^{4}$ National \\ Center for Biotechnology, Life Science \\ and Environmental Research Institute, \\ King Abdulaziz City for Science and \\ Technology, Riyadh, Saudi Arabia; \\ ${ }^{5}$ Laboratory Medicine Department, \\ Faculty of Applied Medical Sciences, \\ Umm Al-Qura University, Makkah, Saudi \\ Arabia
}

Correspondence: Thimappa

Ramachandrappa Lakshmeesha

Department of Biotechnology, Bangalore

University, Bangalore, 560056, Karnataka,

India

Tel +91 8710937464

Email lakshmeeshat6@gmail.com

Mohammad Azam Ansari

Department of Epidemic Disease

Research, Institutes for Research and

Medical Consultations (IRMC), Imam

Abdulrahman Bin Faisal University,

Dammam, 3144I, Saudi Arabia

Tel +966580306835

Email maansari@iau.edu.sa
Purpose: 4-Hydroxyisophthalic acid (4-HIA) is a bioactive compound present in the roots of Decalepis hamiltonii, which has attracted considerable attention in attenuating oxidative stress-related neurodegenerative diseases. However, its efficacy is limited because of its low solubility and bioavailability. Therefore, the present study aimed to encapsulate 4-HIA using biocompatible copolymer polylactide-co-glycolide (PLGA) and evaluate its antioxidant and neuroprotective potential.

Methods: The nanoparticles (NPs) were fabricated by solid/oil/water (s/o/w) emulsion technique and characterized using XRD, SEM, HR-TEM, and FTIR spectroscopy. Antioxidant assays such as 1,1 diphenyl-2-picrylhydrazyl (DPPH), superoxide, and hydroxyl radical scavenging ability were performed to assess the antioxidant potential of the fabricated NPs.

Results: The bioactive component, 4-HIA, was efficiently encapsulated by the PLGA polymer and was found to be spherical and smooth with a size $<10 \mathrm{~nm}$. 4-HIA showed better scavenging capability in DPPH and superoxide assays as compared to 4-HIA encapsulated PLGA and butylated hydroxytoluene (BHT). In contrast, 4-HIA encapsulated PLGA NPs exhibited a significant hydroxyl radical scavenging activity than 4-HIA and BHT alone. Further, the encapsulated NPs efficiently curtailed hydrogen peroxide $\left(\mathrm{H}_{2} \mathrm{O}_{2}\right)$-induced cytotoxicity in PC12 cells.

Conclusion: Our findings indicate that 4-HIA encapsulated PLGA NPs might be a therapeutic intervention towards the effective management of oxidative stress as it has exhibited efficient neuroprotective potential against $\mathrm{H}_{2} \mathrm{O}_{2}$-induced oxidative stress in $\mathrm{PC} 12$ cells.

Keywords: 4-Hydroxyisophthalic acid, polylactic-co-glycolic acid, nanoencapsulation, PC12 cells, cytotoxicity

\section{Introduction}

Plant extracts and their bioactive constituents are used as potential therapeutics for the treatment of various diseases. ${ }^{1}$ Decalepis hamiltonii Wight \& Arn. is a climbing shrub belonging to the family Apocynaceae and commonly called Makali beru in South India. $^{2}$ The root extract of $D$. hamiltonii is an important source of phenolic compounds. $^{3}$ 4-Hydroxyisophthalic acid (4-HIA), a novel antioxidant compound and one of the major phenolic constituents in D. hamiltonii extract, that exhibits potent-free radical quenching ability, cytoprotective and cardioprotective activity. ${ }^{4,5}$ Our earlier studies and others, revealed the neuroprotective potential of 4-HIA in ameliorating oxidative stress in the aging rat brain and neurodegeneration in drosophila. ${ }^{6,7}$ Poor solubility and low bioavailability of 4-HIA presents a challenge 
to exhibit neuroprotection because of its reduced ability to permeate the blood-brain barrier (BBB) (Sowbhagya et al unpublished data).

Nanoformulations are an alternative platform of drug delivery system, which improves the cellular uptake of hydrophilic and hydrophobic compounds, together with shelf-life. Polymer-based nanofabrication has fascinated the scientific community because of their diverse application in biomedical sciences to treat neurodegenerative and cardiovascular diseases. ${ }^{8}$ Recently, synthetic and natural polymers like polyethylene glycol (PEG), polylactic-coglycolic acid (PLGA), chitosan, and polysaccharides have been approved by the Food and Drug Administration (FDA) of the United States and employed extensively in designing nanoscale materials. Amongst all these, PLGA, due to its enhanced biodegradability and biocompatibility have been widely used as drug delivery systems like microspheres, pellets, films, matrixes, blends, and nanoparticles (NPs). ${ }^{9,10}$ Besides, PLGA have been approved for 14 pharmaceutical and biomedical properties by the FDA. ${ }^{11}$ Several studies have documented that PLGA loaded NPs has offered enhanced antioxidant and cytotoxic activities. $^{12,13}$

The therapeutic targets are localized in the central nervous system, limiting the passage of drugs to cross the BBB. Hence, 4-HIA encapsulated PLGA NPs may serve as a promising alternative for neuroprotection. Based on these facts, the present study was designed to fabricate 4-HIA-PLGA NPs, and investigate their antioxidant and neuroprotective potential against $\mathrm{H}_{2} \mathrm{O}_{2}$-induced toxicity in PC12 cells.

\section{Materials and Methods}

\section{Chemicals and Reagents}

PLGA, 1.1-diphenyl-2-picrylhydrazyl (DPPH), 4-hydroxyisophthalic acid (4-HIA) were obtained from Sigma Aldrich (St. Louis, Mo, USA.). Ham's FK12 medium, fetal bovine serum (FBS), L-glutamine, antibiotic-antimycotic solution, 3(4,5-dimethylthiazol-2)-2, 5-diphenyl tetrazolium bromide (MTT) were procured from Himedia (India). All organic solvents (spectral grade) and general chemicals (analytical grade) were purchased from local companies.

\section{Preparation of 4-HIA Encapsulated PLGA NPs}

PLGA NPs were synthesized by the solid-in-oil-in-water (s/o/w) emulsion method. ${ }^{14} 45 \mathrm{mg}$ of PLGA with a 50:50 ratio of lactic to glycolic acid was mixed with dichloromethane for $6 \mathrm{~h}$ to attain a uniform concentration of PLGA. 5mg of 4-HIA was then suspended to PLGA solution and sonicated for $1 \mathrm{~min}$ at $55 \mathrm{~W}$ to obtain solid in oil primary emulsion (organic phase). This primary emulsion was sonicated again at $55 \mathrm{~W}$ for $2 \mathrm{~min}$ after the addition of $20 \mathrm{~mL}$ polyvinyl alcohol (PVA, 1\% $\mathrm{w} / \mathrm{v})$ solution. The resultant nano-sized particles were agitated in the emulsion for $3 \mathrm{~h}$ for the evaporation of the solvent. The obtained secondary emulsion was centrifuged for $15 \mathrm{~min}$ at $15,000 \mathrm{~g}$. These newly synthesized NPs were washed thrice using deionized distilled water and were resuspended finally in deionized water and dried with the help of a lyophilizer. The synthesized NPs were kept at $4^{\circ} \mathrm{C}$ for further experiments.

\section{Characterization of NPs Percentage Yield of the NPs}

The percentage yield was determined as the ratio between the weight of dried 4-HIA encapsulated PLGA NPs and the total weight of utilized 4-HIA and PLGA. The yield was calculated using the given formula. ${ }^{15}$

$$
\begin{aligned}
& \text { Percentage } \\
& \text { yield }
\end{aligned}=\frac{\text { Weight of Nanoparticle obtained }}{\text { Weight of } 4-\text { HIA and PLGA used }} \times 100
$$

\section{X-Ray Diffraction (XRD) Measurement}

The X-ray diffractograms of 4-HIA, 4-HIA encapsulated PLGA and blank PLGA NPs samples (1mg) were grounded with the help of mortar and pestle. The obtained powdered samples were packed evenly into a cavity glass slide. The glass slide was placed in a sample holder, and readings were recorded in an X-ray diffractometer (Shimadzu XRD 7000 maxima) using Ni-filtered CuKa radiation $(35 \mathrm{kV}, 15 \mathrm{~mA})$

\section{Scanning Electron Microscopy (SEM)}

SEM (TM 3000, Hitachi, Japan) was employed to study the surface morphology of 4-HIA, 4-HIA encapsulated PLGA, and blank PLGA. The 4-HIA, 4-HIA encapsulated PLGA, and standard PLGA NPs were mounted on an aluminium stub with double-sided carbon tape. The images at desired magnification were captured on SEM mode.

\section{High-Resolution Transmission Electron Microscopy (HR-TEM)}

The size distribution and surface morphology of the NPs, along with their selected area electron diffusion (SAED) 
patterns, were assessed by HR-TEM (JEOL JEM 2100, Hitachi, Japan). The samples $(1 \mathrm{mg} / \mathrm{mL})$ were dispersed in HPLC-grade water by means of an ultrasonic bath. The suspensions were dropped onto $0.037 \mathrm{~mm}$ copper grids, and excess water is sucked onto the sterile filter paper and air-dried before viewing under TEM.

\section{Spectroscopic Characterization}

The Fourier transform Infrared (FTIR) spectra of 4-HIA, 4-HIA encapsulated PLGA and blank PLGA NPs were obtained on Cary 630 FTIR (Agilent Technologies) equipped with a smart iTR diamond ATR device. Samples $(1 \mathrm{mg})$ were crushed in a sterile mortar and pestle. The obtained fine powdered samples were loaded onto the mounting plate so as to cover the exposed surface of the crystal using a clean spatula. The pressure arm is swung over the top of the sample, and the knob rotated until it just touches the sample. Spectra were measured in the $400-4000 \mathrm{~cm}^{-1}$ scanning range at a resolution of $1 \mathrm{~cm}^{-1}$.

\section{Antioxidant Assays DPPH Radical Scavenging Activity}

DPPH assay was accomplished following the method of Shon et al with slight modifications. ${ }^{16}$ Briefly, $0.5 \mathrm{~mL}$ of 4-HIA and 4-HIA encapsulated PLGA each was added to $1 \mathrm{~mL}$ of DPPH solution $(0.1 \mathrm{mM}$, in $95 \%$ ethanol $)$ and incubated at RT for $20 \mathrm{~min}$. The absorbance was recorded at $517 \mathrm{~nm}$ against a suitable blank.

$$
\begin{aligned}
\text { Scavenging effect }(\%)= & \frac{\mathrm{Abs}_{\mathrm{Control}(517)}-\mathrm{Abs}_{\text {Sample(517) }}}{\mathrm{Abs}_{\mathrm{Control}(517)}} \\
& \times 100
\end{aligned}
$$

Where Abs control $=$ absorbance of the control (reacting mixture without the test sample) and Abs sample = absorbance of reacting mixture with the test sample.

\section{Superoxide Radical Scavenging Activity}

Superoxide radical scavenging assay was performed according to the procedure of Nishikimi et al. ${ }^{17}$ About $1 \mathrm{~mL}$ of nitroblue tetrazolium (NBT) solution $(156 \mu \mathrm{M})$, $1 \mathrm{~mL}$ of nicotinamide adenine dinucleotide (NADH) solution $(468 \mu \mathrm{M})$ were added to 4-HIA, and 4-HIA encapsulated PLGA NPs. The reaction was started by the addition of $100 \mu \mathrm{L}$ of phenazine methosulfate (PMS) solution (60 $\mu \mathrm{M}$ PMS). Each reagent was prepared separately in $100 \mathrm{mM}$ phosphate buffer at $\mathrm{pH}$ 7.4. The reaction mixture was incubated for $5 \mathrm{~min}$ at $25^{\circ} \mathrm{C}$, and the absorbance was observed at $560 \mathrm{~nm}$. $\begin{aligned} \text { Scavenging effect }(\%)= & \frac{\operatorname{Abs}_{\operatorname{Control}(560)}-\mathrm{Abs}_{\text {Sample(560) }}}{\operatorname{Abs}_{\operatorname{Control}(560)}} \\ & \times 100\end{aligned}$

Where Abs control $=$ absorbance of the control (reacting mixture without the test sample) and Abs sample $=$ absorbance of reacting mixture with the test sample.

\section{Hydroxyl Radical Scavenging Activity}

The protocol of Halliwell and Gutteridge was adopted to carry out the hydroxyl radical scavenging assay. ${ }^{18}$ Briefly, different concentrations of $20 \mu \mathrm{L}$ of 4-HIA and 4-HIA encapsulated PLGA were added to a reaction mixture containing $120 \mu \mathrm{L}$ of $20 \mathrm{mM}$ deoxyribose, $400 \mu \mathrm{L}$ of phosphate buffer $(0.1 \mathrm{M}), 40 \mu \mathrm{L}$ of $20 \mathrm{mM} \mathrm{H}_{2} \mathrm{O}_{2}$, and $40 \mu \mathrm{L}$ of $500 \mu \mathrm{M} \mathrm{FeSO}$. The final volume was made up to $800 \mu \mathrm{L}$ with distilled water. The resultant mixture was incubated for $30 \mathrm{~min}$ at $37^{\circ} \mathrm{C}$. After the incubation, the reaction was discontinued by adding 500 $\mu \mathrm{L}$ of $2.8 \%$ trichloroacetic acid (TCA) followed by 400 $\mu \mathrm{L}$ of thiobarbituric acid (TBA) solution $(0.6 \%)$. The tubes were then incubated for $20 \mathrm{~min}$ in a boiling water bath, and the absorbance was recorded at $532 \mathrm{~nm}$. The percentage of hydroxyl radical scavenging activity was obtained using the following formula.

$$
\begin{aligned}
\text { Scavenging effect }(\%)= & \frac{\mathrm{Abs}_{\mathrm{Control}(532)}-\mathrm{Abs}_{\text {Sample(532) }}}{\operatorname{Abs}_{\mathrm{Control}(532)}} \\
& \times 100
\end{aligned}
$$

Where $A b s_{\text {control }}=$ absorbance of the control (reacting mixture without the test sample) and Abs sample = absorbance of reacting mixture with the test sample.

\section{Cell Culture and Drug Treatment}

Undifferentiated PC12 cells were procured from National Center for Cell Science, Pune, India and were maintained in Ham's F12K medium. The medium was supplemented with $15 \%$ FBS, $1 \%$ antibiotic-antimycotic solution, and $2 \mathrm{mM} \mathrm{L}$-glutamine solution at $37^{\circ} \mathrm{C}$ in a humidified atmosphere $\left(5 \% \mathrm{CO}_{2}\right)$. The cells were cultured in poly-L-lysine coated culture flasks, and the medium was changed every three days. Light microscopy was used to check the confluency of the viable growing cells. Upon attaining cell density at $70-80 \%$ confluency, the cells were dislodged with $0.25 \%$ trypsin, and cells were seeded in an appropriate density following the experimental protocol. The viability of PC12 cells exposed to $\mathrm{H}_{2} \mathrm{O}_{2}$ was measured by treating the 
cells with increasing concentrations ranging from 100 to $1000 \mu \mathrm{M}$ for $24 \mathrm{~h}$ to find the $\mathrm{IC}_{50}$ value. To evaluate the protective effects of PLGA encapsulated NPs, cells were pre-treated with 4-HIA, and 4-HIA encapsulated PLGA NPs $(50-300 \mu \mathrm{g} / \mathrm{mL})$ for $24 \mathrm{~h}$ prior to the exposure to $\mathrm{H}_{2} \mathrm{O}_{2}$ for $24 \mathrm{~h}$. Cell viability was measured by MTT assay as mentioned below.

\section{MTT Assay}

MTT assay was carried out to observe the $\mathrm{H}_{2} \mathrm{O}_{2}$-induced cell toxicity, which is a sensitive method to evaluate the metabolic status of the cells. ${ }^{19}$ Initially, cultured PC12 cells were plated in triplicates at a cell density of $1 \times 10^{6}$ cells/well for $24 \mathrm{~h}$ in a 96-well plate. The cells were treated with different concentrations of 4-HIA, and 4-HIA encapsulated PLGA for $24 \mathrm{~h}$ before the exposure of $500 \mu \mathrm{M} \mathrm{H}_{2} \mathrm{O}_{2}$ for 24 h. $20 \mu \mathrm{L}$ MTT solution $(0.25 \%)$ was added at the indicated time points to the cells and incubated at $37^{\circ} \mathrm{C}$ for 4 h. $100 \mu \mathrm{L}$ DMSO was added after discarding the medium. The absorbance was determined at $570 \mathrm{~nm}$ (Model-3550, Bio-Rad). Experiments were carried out in triplicates. The results were expressed as the percentage of absorbance against the non-treated control cells.

\section{Statistical Analysis}

Results are represented as mean $\pm \operatorname{SE~}(n=3)$. One-way and two-way ANOVA were performed, followed by Tukey's test for comparing the differences between means using SPSS 16.0 software package. A probability value of $\mathrm{p}<0.05$ was considered statistically significant.

\section{Results}

\section{Synthesis and Characterization of NPs Yield of NPs}

4-HIA encapsulated PLGA NPs were effectively synthesized using solvent evaporation process, and its consistency was evaluated for various batches. The yield of the 4-HIA encapsulated PLGA NPs were found to be $31 \%$.

\section{X-Ray Diffraction (XRD) Measurement}

The XRD patterns for 4-HIA, blank PLGA, and 4-HIA encapsulated PLGA NPs are represented in Figure 1.

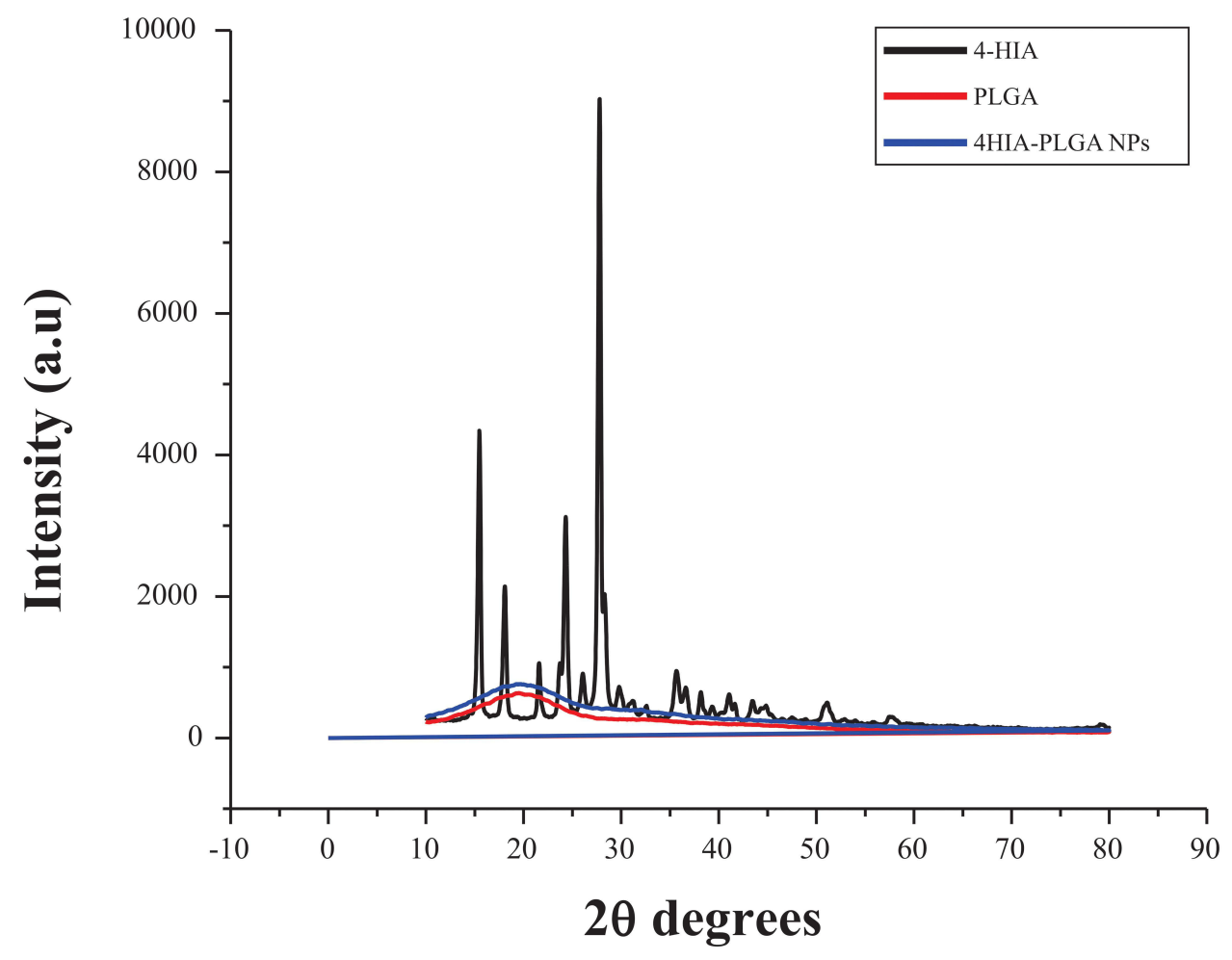

Figure I XRD spectra of 4-HIA, PLGA, 4-HIA encapsulated PLGA nanoparticles. 
The diffraction pattern peaks at $15,18,22,25$, and 28 depict the crystalline nature of 4-HIA. Such characteristic peaks were not noticed in PLGA, and 4-HIA encapsulated PLGA NPs due to their amorphous nature.

\section{SEM Analysis}

The SEM images of 4-HIA, blank PLGA, and 4-HIA encapsulated PLGA NPs are represented in Figure 2. The images revealed that blank PLGA and 4-HIA

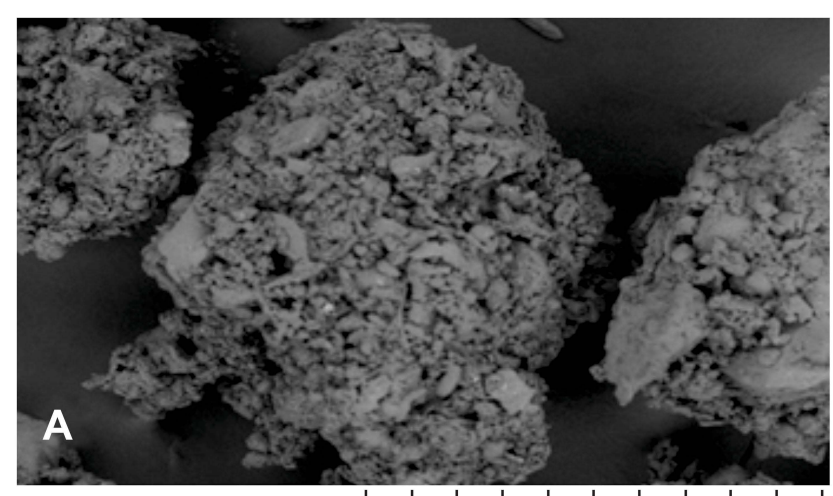

TM3000_7364

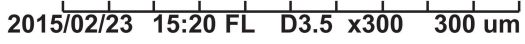

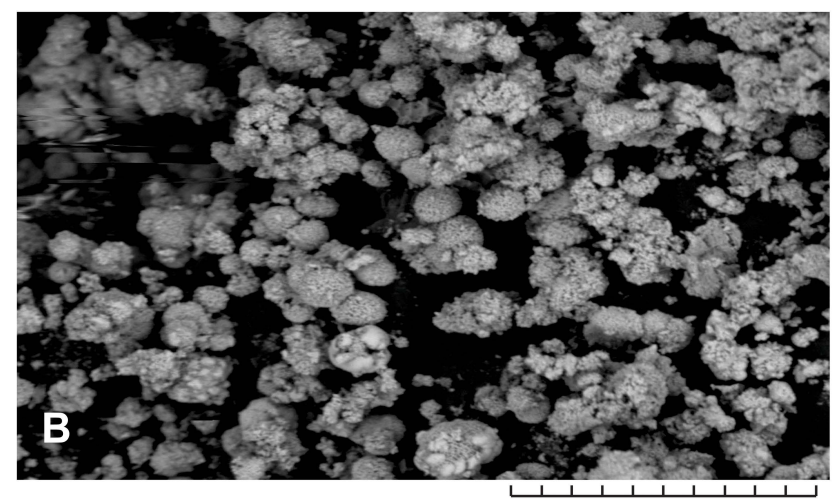

TM3000_7447 2015/03/01 18:01 FL \begin{tabular}{cccccccc}
\hline & D3.7 & 1 & 1 & 1 & 1 & 1 \\
\hline
\end{tabular}

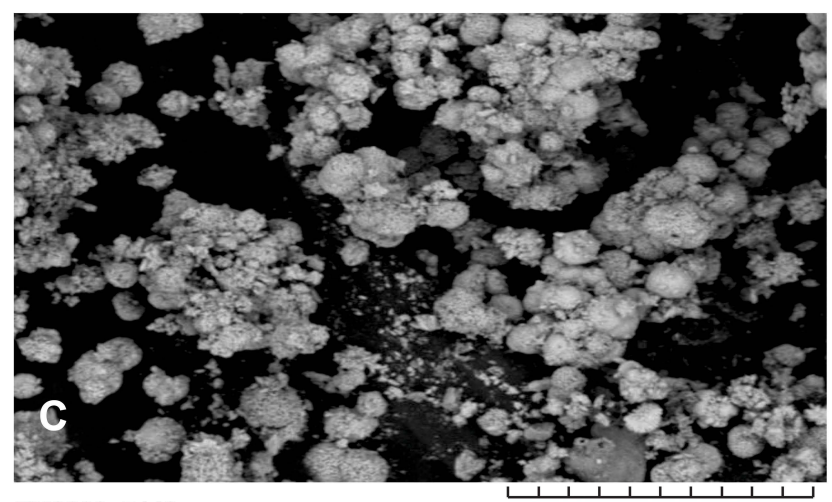

TM3000_7448 2015/03/01 18:02 FL D3.6 x1.2k 50 um

Figure 2 SEM images of (A) 4-HIA (B) PLGA and (C) 4-HIA encapsulated PLGA nanoparticles. encapsulated PLGA NPs were spherical with a smooth surface, whereas 4-HIA crystals showed irregular shape and pattern.

\section{HR-TEM Analysis}

The size of the 4-HIA encapsulated PLGA NPs was found to be $<10 \mathrm{~nm}$. HRTEM imaging was employed to elucidate the morphology of 4-HIA, and 4-HIA encapsulated PLGA NPs and the images are shown in Figure 3A and C. 4-HIA encapsulated PLGA NPs were spherical and uniformly encapsulated within the PLGA matrix. The structural characteristics were further elucidated by selected area electron diffraction (SAED) patterns. The SAED pattern reveals the amorphous nature of 4-HIA encapsulated PLGA NPs where the diffraction rings are blurred (Figure 3B). While Figure 3D represents the crystalline nature of 4-HIA. The patterns of SAED for crystalline 4-HIA were indexed accordingly based on their $d$-spacings which were found to be $0.3596 \mathrm{~nm}, 0.2287 \mathrm{~nm}, 0.1954 \mathrm{~nm}$, $0.1688 \mathrm{~nm}, 0.1320 \mathrm{~nm}, 0.1137 \mathrm{~nm}, 0.1017 \mathrm{~nm}$.

\section{Spectroscopic Characterization}

The intermolecular interaction between blank PLGA, 4-HIA, and 4-HIA encapsulated PLGA NPs were determined by FTIR spectroscopy. The characteristic spectra of the 4-HIA indicated carbonyl stretch $(\mathrm{C}=\mathrm{O})$ at $1649.32 \mathrm{~cm}^{-1}$ and $\mathrm{C}=\mathrm{C}$ stretch at $1582.26 \mathrm{~cm}^{-1}$ (Figure 4A). The characteristic spectra of PLGA as shown in Figure 4B indicated $-\mathrm{CH}_{1}-\mathrm{CH}_{2}-\mathrm{CH}_{3}$ - stretching $\left(2800-3000 \mathrm{~cm}^{-1}\right), \mathrm{C}=\mathrm{O}$ stretch $\left(1700-1800 \mathrm{~cm}^{-1}\right)$, $\mathrm{C}-\mathrm{H}$ stretch at $2918.927 \mathrm{~cm}^{-1}$, and C-O stretch at 1700 $1800 \mathrm{~cm}^{-1}$. 4-HIA encapsulated PLGA NPs exhibited similar characteristic spectra as that of PLGA with $\mathrm{C}=\mathrm{O}$ stretch at $1747.71 \mathrm{~cm}^{-1}$, O-H stretch at $2949.15 \mathrm{~cm}^{-1}$, and $2995.65 \mathrm{~cm}^{-1}$ (Figure 4C).

\section{Antioxidant Assays DPPH Assay}

The DPPH radical scavenging ability is represented in Figure 5. The 4-HIA and 4-HIA encapsulated PLGA NPs exhibited concentration-dependent antiradical activity. The 4-HIA was found to be significantly more effective free radical scavenging agent as evident by its lower $\mathrm{IC}_{50}$ value of $239.3 \pm$ $2.3 \mu \mathrm{g} / \mathrm{mL}$ against BHT. 4-HIA encapsulated PLGA $(59 \pm 0.5 \mu \mathrm{g} / \mathrm{mL})$ also revealed significant scavenging 

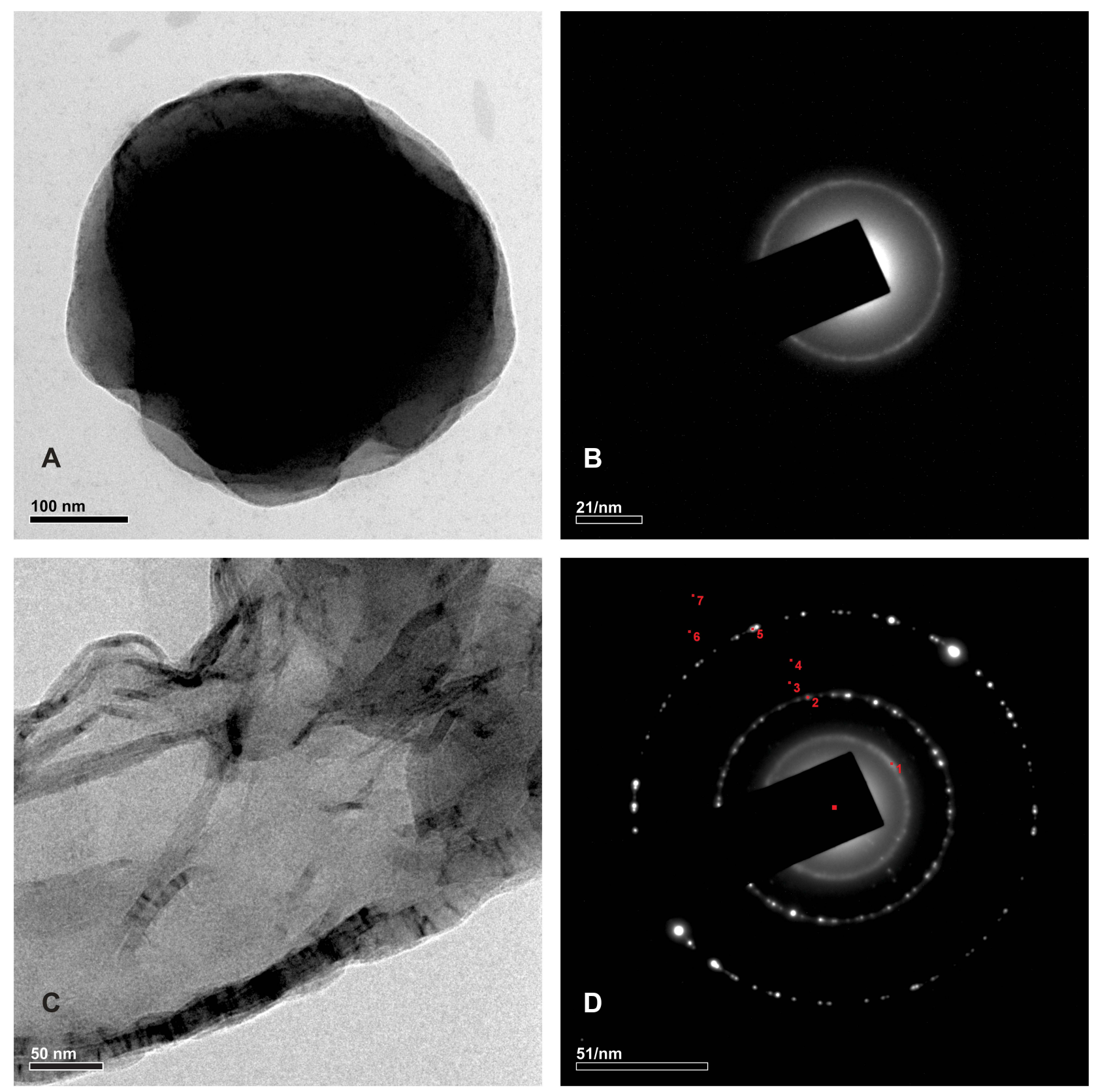

Figure 3 HR-TEM images of (A and $\mathbf{C})$ 4-HIA encapsulated PLGA nanoparticles and 4-HIA. Selected area electron diffraction patterns of (B and D) 4-HIA encapsulated PLGA nanoparticles and 4-HIA.

activity compared to the BHT $(54 \pm 0.3 \mu \mathrm{g} / \mathrm{mL})$ at $1000 \mu \mathrm{g} / \mathrm{mL}$.

\section{Superoxide Radical Scavenging Activity}

The scavenging activity revealed a significant dosedependent relationship with 4-HIA exhibiting maximum scavenging activity (64\%) followed by 4-HIA encapsulated PLGA NPs (58\%) and BHT (53.5\%) (Figure 6). The $\mathrm{IC}_{50}$ values of 4-HIA and 4-HIA encapsulated
PLGA NPs were found to be $314.3 \pm 1.4 \mu \mathrm{g} / \mathrm{mL}$ and $386.5 \pm 1.8 \mu \mathrm{g} / \mathrm{mL}$.

\section{Hydroxyl Radical-Scavenging Activity}

The significant feature of the hydroxyl radical scavenging activity is that 4-HIA encapsulated PLGA NPs exhibited higher inhibition (76\%) compared to 4-HIA (57\%) and BHT (74.5\%) with an $\mathrm{IC}_{50}$ value of $453.7 \pm 2.2 \mu \mathrm{g} / \mathrm{mL}$ (Figure 7). 

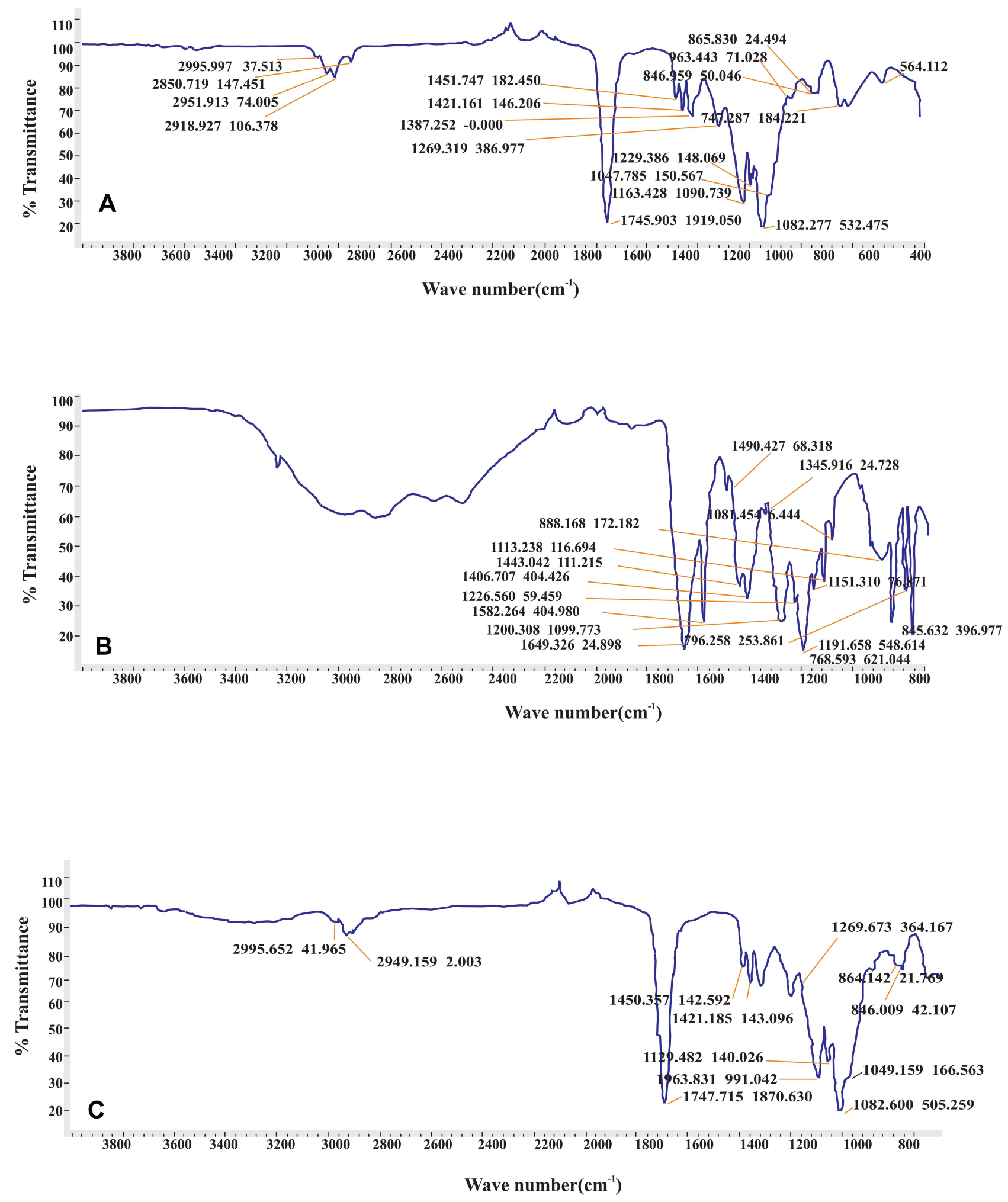

Figure 4 FTIR spectra of (A) PLGA (B) 4-HIA and (C) 4-HIA encapsulated PLGA nanoparticles. 


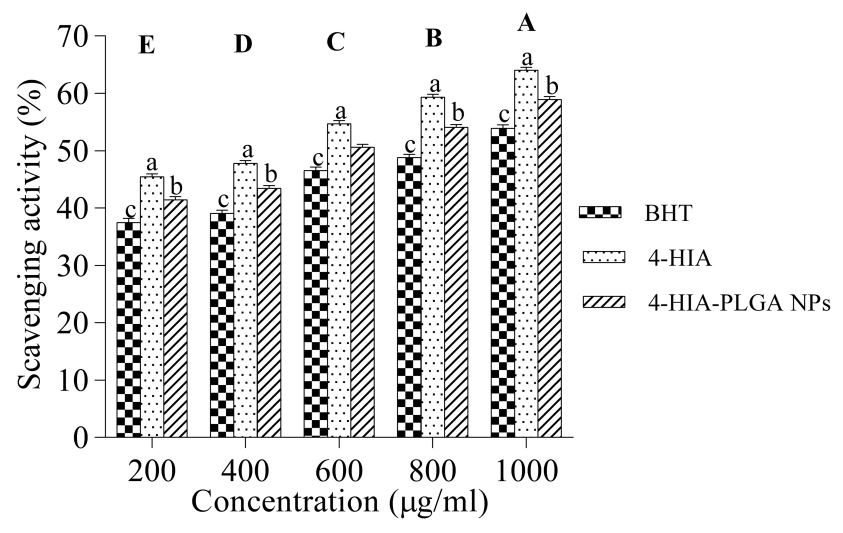

Figure 5 DPPH radical scavenging activity. Values are represented as mean \pm S.E $(n=3)$. Significance between the samples is represented in lower case $(p<0.05)$ and between the concentrations is represented in upper case. Those not sharing the same letters are significantly different.

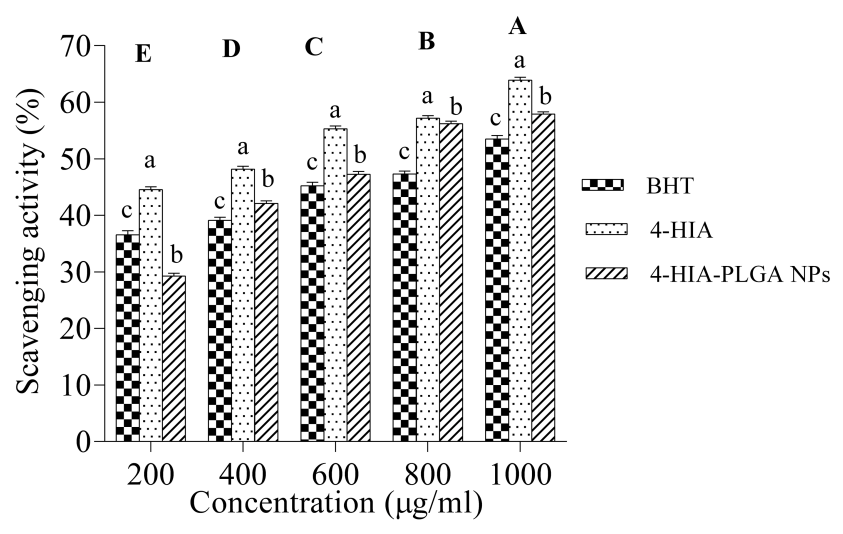

Figure 6 Superoxide radical scavenging activity. Values are represented as mean $\pm S$. $E(n=3)$. Significance between the samples is represented in lower case $(p<0.05)$ and between the concentrations is represented in upper case. Those not sharing the same letters are significantly different.

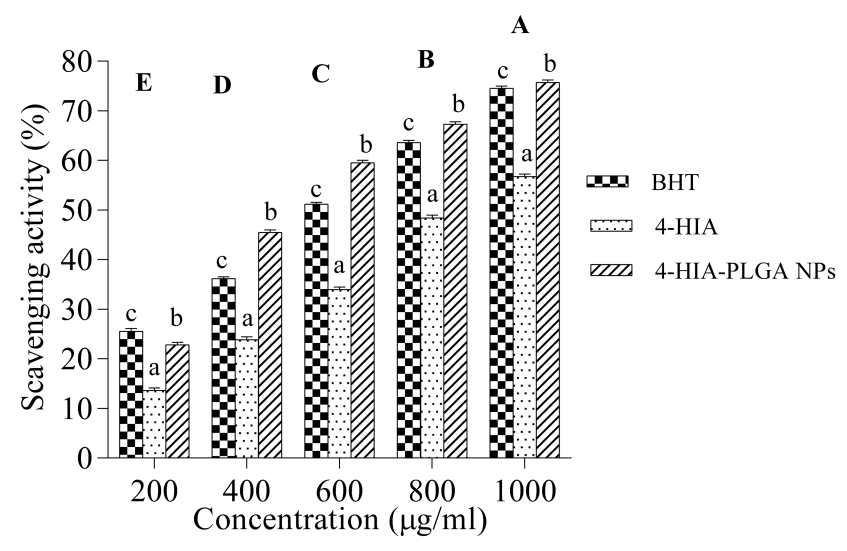

Figure 7 Hydroxyl radical scavenging activity. Values are represented as mean \pm S.E $(n=3)$. Significance between the samples is represented in lower case $(p<0.05)$ and between the concentrations is represented in upper case. Those not sharing the same letters are significantly different.

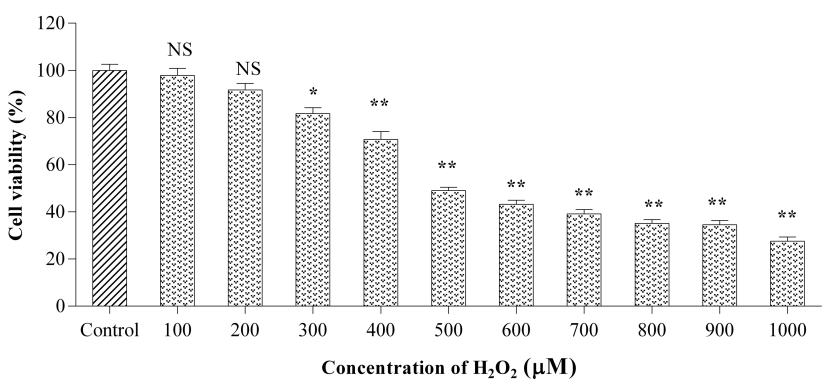

Figure 8 Effect of $\mathrm{H}_{2} \mathrm{O}_{2}$ on cell viability in $\mathrm{PCl} 2$ cell lines induced oxidative stress. Values are expressed as mean \pm S.E $(n=3)$. $* * P<0.01$ compared to control. $* P<0.05$ compared to control.

\section{In vitro Studies}

\section{Effect of $\mathrm{H}_{2} \mathrm{O}_{2}$ on Cell Viability and Morphology}

The viability of PC12 cells was evaluated by MTT assay, which exhibited dose-dependent cytotoxicity, as shown in Figure 8. The cells were treated with different concentrations of $\mathrm{H}_{2} \mathrm{O}_{2}$ for $24 \mathrm{~h}$. The $\mathrm{IC}_{50}$ value was found to be $500 \mu \mathrm{M}$. Therefore, this concentration was fixed for further experiments. Cell morphology was observed using a phase contrast microscope. $\mathrm{H}_{2} \mathrm{O}_{2}$-treated cells revealed cell loss, shrinkage, irregular shape, detachment, and membrane blebbing (Figure 9).

\section{Effect of 4-HIA Encapsulated PLGA NPs Against $\mathrm{H}_{2} \mathrm{O}_{2}$-Mediated Cytotoxicity}

To assess the effect of 4-HIA encapsulated PLGA NPs on $\mathrm{H}_{2} \mathrm{O}_{2}$-mediated cytotoxicity, cells were treated with various concentrations of PLGA/4-HIA encapsulated PLGA NPs for $24 \mathrm{~h}$ before to $\mathrm{H}_{2} \mathrm{O}_{2}$ exposure. As shown in Figure 10, the viability of the cells exposed to $\mathrm{H}_{2} \mathrm{O}_{2}$ was reduced to $50 \%$ with respect to control. 4-HIA and 4-HIA encapsulated PLGA remarkably curtailed $\mathrm{H}_{2} \mathrm{O}_{2}$-induced toxicity in a dose-dependent manner and restored the cell viability to $84 \%$ and $94 \%$ over $\mathrm{H}_{2} \mathrm{O}_{2}$-treated cells, respectively.

\section{Discussion}

4-HIA is a potent phenolic compound of $D$. hamiltonii extract exhibiting a broad range of biological functions like antioxidant and cytotoxic activities. However, the poor water solubility of 4-HIA has limited its application as a promising therapeutic candidate in the management of neurodegenerative ailments. In recent years, novel drug 

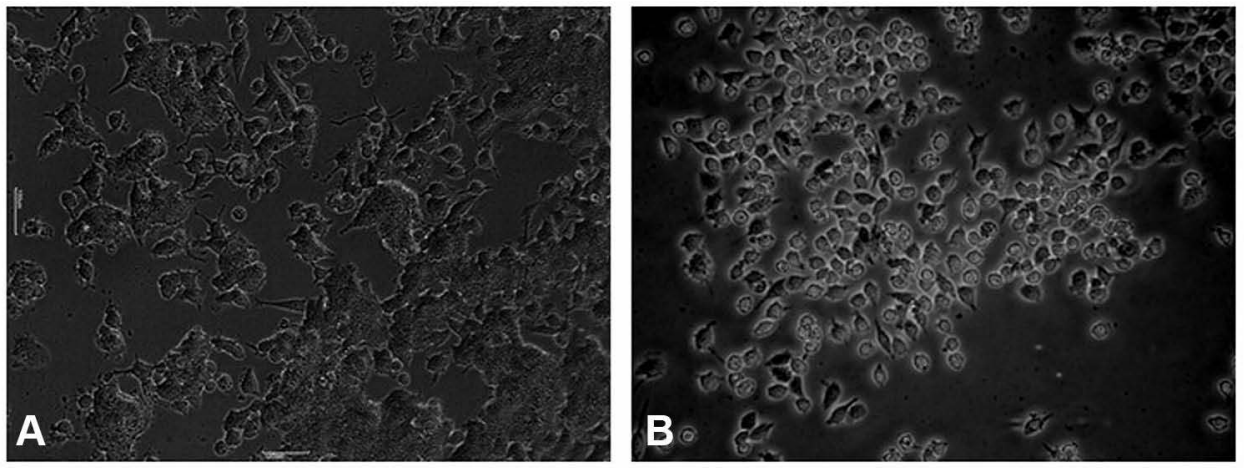

Figure 9 Images of $(\mathbf{A})$ Control $(\mathbf{B}) \mathrm{H}_{2} \mathrm{O}_{2}$ treated $\mathrm{PCl} 2$ cells under phase-contrast microscope (40X).

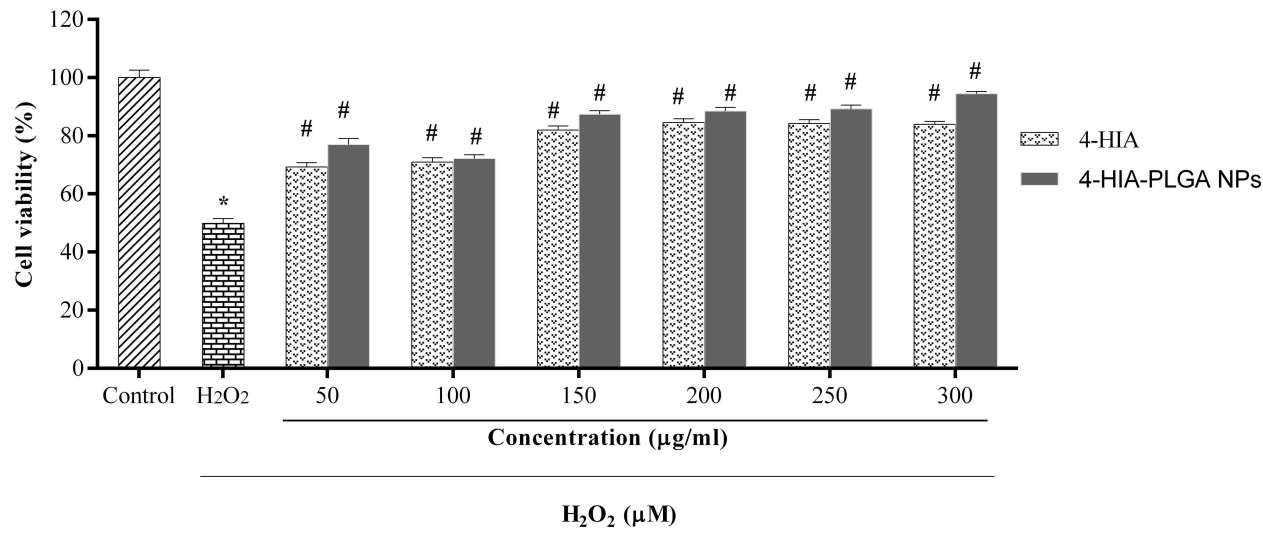

Figure 10 Cell viability of $\mathrm{PCI} 2$ cells treated with different concentrations of 4-HIA and 4-HIA encapsulated PLGA nanoparticles against $\mathrm{H}_{2} \mathrm{O}_{2}$ induced cytotoxicity. Values are expressed as the mean $\pm S . E(n=3)$. ${ }^{*} P<0.01$ compared to control, ${ }^{\#} \mathrm{P}<0.05$ compared to $\mathrm{H}_{2} \mathrm{O}_{2}$ treated cells.

delivery strategies have been adopted for natural phytocompounds for improving their bioavailability. PLGA, a biocompatible and biodegradable polymer, has attracted researchers for the formulation of hydrophobic compounds. ${ }^{10,20}$ In the current study, we hypothesized that 4-HIA NPs employing PLGA polymer might serve as a novel strategy towards neuroprotection. Hence, for the first time, 4-HIA-PLGA NPs were synthesized, and their neuroprotective efficacy was evaluated in the $\mathrm{PC} 12$ cells against $\mathrm{H}_{2} \mathrm{O}_{2}$-induced toxicity.

In our study, 4-HIA encapsulated PLGA NPs were fabricated by a s/o/w solvent evaporation method with PLGA as the carrier. PVA is a routinely employed stabilizer for PLGA polymer and used as a surfactant in pharmaceutical formulations to stabilize the nanoparticle emulsion leading to an increase in solubility of the drug without agglomeration. ${ }^{21,22}$

In order to know the nature of 4-HIA encapsulated PLGA NPs, XRD was performed. The blank PLGA revealed no characteristic peak, but the distinct peaks were observed for 4-HIA, which depicts the crystalline nature of 4-HIA, while the encapsulated NPs fail to exhibit the characteristic peaks indicating the effective encapsulation of the compound in the PLGA. Therefore, in PLGA NPs, the 4-HIA was present in the amorphous phase and may be homogeneously dispersed in the PLGA matrix suggesting its amorphous nature. Our results are parallel with Pool et al. ${ }^{23}$ Our findings also indicated that the intermolecular interactions among PLGA polymer chains confers an amorphous character to 4-HIA after encapsulation. A related phenomenon was noticed with the majority of the crystalline drugs possessing amorphous nature when encapsulated into PLGA NPs. ${ }^{24,25}$

The NPs structure plays a vital role in understanding their interaction and adhesion with the cells. Hence, SEM and HR-TEM were performed to determine the surface morphology and shape of 4-HIA encapsulated PLGA NPs. The NPs were spherical with a smooth surface and homogeneous shapes. The morphology of PLGA NPs obtained is in accordance with the reports of Mathew 
et al, Pool et al, and Arasoglu et al. ${ }^{23,26,27}$ Our observations on diffraction ring pattern of SAED were obtained for 4-HIA corresponds with the XRD peaks of 4-HIA and confirmed its crystalline nature. While the halo ring pattern for the fabricated NPs revealed its amorphous nature. Thus, the obtained patterns of SAED were complementing well with the studies of Kaur et al. ${ }^{28}$

Following this, FTIR transmittance was performed to identify the functional groups of compounds based on the characteristic vibrations of the bonds. The spectra obtained for free PLGA NPs showed characteristic bands consistent with the studies of Erbetta et al and Mondal et al. ${ }^{29,30}$ However, in the encapsulated NPs, the $\mathrm{C}=\mathrm{O}$ peak was slightly shifted to a higher wavelength. This could be due to the formation of intermolecular hydrogen bonds between the $\mathrm{C}=\mathrm{O}$ bond of PLGA and the $\mathrm{O}-\mathrm{H}$ bond of 4-HIA.

The DPPH assay was employed to assess the freeradical quenching ability of 4-HIA encapsulated PLGA NPs compared to 4-HIA. Our findings revealed that 4-HIA showed better scavenging activity compared to 4-HIA encapsulated PLGA and BHT, which may be due to prolonged time taken by the encapsulated 4-HIA to leach out into the DPPH solution. Furthermore, PLGA encapsulation does not degrade the antioxidant property of 4-HIA. Our reports agree with the studies of Mathew et $\mathrm{al}^{27}$ wherein curcumin encapsulated PLGA NPs showed less activity than raw curcumin.

Superoxide and hydroxyl radicals are the major free radicals generated as a result of metabolic reactions. ${ }^{31}$ In our study, 4-HIA exhibited a higher ability to scavenge the superoxide radicals over the 4-HIA encapsulated PLGA and BHT. The decreased activity in encapsulated NPs may be attributed to the slow release of the compound into the reaction mixture. While hydroxyl radical scavenging activity was more evident in 4-HIA encapsulated PLGA NPs, which may be attributed to the conversion of $\mathrm{H}_{2} \mathrm{O}_{2}$ to $\mathrm{H}_{2} \mathrm{O}^{32}$

Numerous studies have demonstrated that oxidative stress (OS) is a major cause of cell damage in neurological disorders. ${ }^{33}$ Reactive oxygen species (ROS) damage biological molecules, leading to apoptosis or necrotic cell death. $^{34,35}$ Thus, curtailing these ROS or inhibiting their generation by antioxidants could effectively prevent oxidative cell injury. $\mathrm{H}_{2} \mathrm{O}_{2}$ has been widely employed in in vitro studies as an inducer of $\mathrm{OSS}^{36,37} \mathrm{H}_{2} \mathrm{O}_{2}$ exposure to PC12 cells leads to disparity in energy metabolism due to the oxidation of proteins and lipids by hydroxyl and peroxyl radicals. Our findings revealed that $\mathrm{H}_{2} \mathrm{O}_{2}$ exposure to the cells exhibited a dose-dependent decrement in cell viability. However, the cells pre-treated with 4-HIA and 4-HIA encapsulated PLGA NPs resulted in the reduction of $\mathrm{H}_{2} \mathrm{O}_{2}$ cytotoxicity, indicating that they significantly inhibited $\mathrm{H}_{2} \mathrm{O}_{2}$-induced toxicity by curtailing OS. 4-HIA encapsulated PLGA NPs have a greater anti-apoptotic potential with respect to 4-HIA, which could be attributed to its enhanced bioavailability and half-life.

\section{Conclusion}

In conclusion, the present study suggests that 4-HIA encapsulated PLGA NPs exhibited a remarkable hydroxyl radical scavenging ability. The encapsulated NPs offered better protection against $\mathrm{H}_{2} \mathrm{O}_{2}$-induced oxidative stress in PC12 cells. These findings suggest that 4-HIA encapsulated PLGA NPs may be a promising strategy for the treatment of neurological disorders. However, further studies have to be carried out in vivo to establish its therapeutic potential for the management of oxidative stress-related ailments.

\section{Acknowledgments}

The authors are grateful to the Department of Microbiology and Biotechnology, Bangalore University, for providing the necessary facilities for carrying out this research work. We acknowledge the Deanship of Scientific Research, Imam Abdulrahman Bin Faisal University, Dammam, Saudi Arabia-[Grant number-Covid19-2020002-IRMC] for financial assistance.

\section{Disclosure}

The authors report no conflicts of interest in this work.

\section{References}

1. Nayaka MH, Sathisha U, Dharmesh SM. Cytoprotective and antioxidant activity of free, conjugated and insoluble-bound phenolic acids from swallow root (Decalepis hamiltonii). Food Chem. 2010;119 (4):1307-1312. doi:10.1016/j.foodchem.2009.08.044

2. Anupama SK, Sowbhagya R, Bhagyalakshmi D, Vijay K, Ravikiran T. Decalepis hamiltonii protects $\mathrm{H} 9 \mathrm{c} 2$ cells against $\mathrm{H}_{2} \mathrm{O}_{2}$ induced oxidative stress and apoptosis through modulating antioxidant status. Med Plants-Int J Phytomed Relat Ind. 2019;11(1):87-94. doi:10.5958/09756892.2019.00007.8

3. Srivastava A, Shivanandappa T. Hepatoprotective effect of the aqueous extract of the roots of Decalepis hamiltonii against ethanol-induced oxidative stress in rats. Hepatol Res. 2006;35 (4):267-275. doi:10.1016/j.hepres.2006.04.011

4. Kariyappa AS, Ramachandregowda S, Anand S, Dundaiah B, Gopinath MM, Tekupalli R. Decalepis hamiltonii and its bioactive compounds protects isoproterenol-induced myocardial oxidative stress in rats. Pharmacogn Mag. 2019;15(64):320-327. doi:10.4103/pm. pm_642_18 
5. Srivastava A, Rao LJM, Shivanandappa T. A novel cytoprotective antioxidant: 4-Hydroxyisophthalic acid. Food Chem. 2012;132 (4):1959-1965. doi:10.1016/j.foodchem.2011.12.032

6. Sowbhagya R, Anupama SK, Bhagyalakshmi D, Anand S, Ravikiran T. Modulatory effects of Decalepis hamiltonii extract and its compounds on the antioxidant status of the aging rat brain. J Pharm Bioallied Sci. 2017;9(1):8-15. doi:10.4103/0975-7406.206219

7. Niveditha S, Shivanandappa T. Neuroprotective action of 4-hydroxyisophthalic acid against paraquat-induced motor impairment involves amelioration of mitochondrial damage and neurodegeneration in Drosophila. Neurotoxicology. 2018;66:160-169. doi:10.1016/j.neuro.2018.04.006

8. Balakrishnan K, Casimeer SC, Ghidan AY, Ghethan FY, Venkatachalam K, Singaravelu A. Bioformulated hesperidin-loaded PLGA nanoparticles counteract the mitochondrial-mediated intrinsic apoptotic pathway in cancer cells. J Inorg Organomet Polym Mater. 2020;31:331-343. doi:10.1007/s10904-020-01746-9

9. Kumar V, Bhatt PC, Rahman M, et al. Fabrication, optimization, and characterization of umbelliferone $\beta$-D-galactopyranoside-loaded PLGA NPs in treatment of hepatocellular carcinoma: in vitro and in vivo studies. Int $J$ Nanomedicine. 2017;12:6747-6758. doi:10.2147/IJN.S136629

10. Mahboob T, Nawaz M, de Lourdes Pereira M, et al. PLGA nanoparticles loaded with Gallic acid-a constituent of Leea indica against Acanthamoeba triangularis. Sci Rep. 2020;10(1):1-12. doi:10.1038/ s41598-020-65728-0

11. Pereira ASBF, de Castro Brito GA, de Souza Lima ML, et al. Metformin hydrochloride-loaded PLGA nanoparticles in periodontal disease experimental model using diabetic rats. Int $J$ Mol Sci. 2018;19(11):3488. doi:10.3390/ijms19113488

12. Vieira MV, Derner RB, Lemos-Senna E. Preparation and characterization of Haematococcus pluvialis carotenoid-loaded PLGA nanocapsules in a gel system with antioxidant properties for topical application. J Drug Deliv Sci Technol. 2020;61:102099. doi:10.1016/j.jddst.2020.102099

13. Adlravan E, Nejati K, Karimi MA, Mousazadeh H, Abbasi A, Dadashpour M. Potential activity of free and PLGA/PEG nanoencapsulated nasturtium officinale extract in inducing cytotoxicity and apoptosis in human lung carcinoma A549 cells. J Drug Deliv Sci Technol. 2021;61:102256. doi:10.1016/j.jddst.2020.102256

14. Sankar P, Telang AG, Suresh S, et al. Immunomodulatory effects of nanocurcumin in arsenic-exposed rats. Int Immunopharmacol. 2013;17(1):65-70. doi:10.1016/j.intimp.2013.05.019

15. Michaud D. Epidemiology of pancreatic cancer. Minerva Chir. 2004;59(2):99-111.

16. Shon MY, Kim TH, Sung NJ. Antioxidants and free radical scavenging activity of Phellinus baumii (Phellinus of Hymenochaetaceae) extracts. Food Chem. 2003;82(4):593-597. doi:10.1016/S03088146(03)00015-3

17. Nishikimi M, Rao NA, Yagi K. The occurrence of superoxide anion in the reaction of reduced phenazine methosulfate and molecular oxygen. Biochem Biophys Res Commun. 1972;46(2):849-854. doi:10.1016/S0006-291X(72)80218-3

18. Halliwell B, Gutteridge JM. Formation of a thiobarbituric-acid-reactive substance from deoxyribose in the presence of iron salts: the role of superoxide and hydroxyl radicals. FEBS Lett. 1981;128 (2):347-352. doi:10.1016/0014-5793(81)80114-7

19. Mosmann T. Rapid colorimetric assay for cellular growth and survival: application to proliferation and cytotoxicity assays. J Immunol Methods. 1983;65(1-2):55-63. doi:10.1016/0022-1759(83)90303-4

20. Hafezi Ghahestani Z, Alebooye Langroodi F, Mokhtarzadeh A, Ramezani M, Hashemi M. Evaluation of anti-cancer activity of PLGA NPs containing crocetin. Artif Cells Nanomed Biotechnol. 2017;45(5):955-960. doi:10.1080/21691401.2016.1198359
21. Wischke C, Schwendeman SP. Principles of encapsulating hydrophobic drugs in PLA/PLGA microparticles. Int J Pharm. 2008;364 (2):298-327.

22. Verderio P, Bonetti P, Colombo M, Pandolfi L, Prosperi D. Intracellular drug release from curcumin-loaded PLGA nanoparticles induces G2/M block in breast cancer cells. Biomacromolecules. 2013;14(3):672-682. doi:10.1021/bm3017324

23. Pool H, Quintanar D, Figueroa JDD, et al. Antioxidant effects of quercetin and catechin encapsulated into PLGA nanoparticles. J Nanomater. 2012;2012:145380. doi:10.1155/ 2012/145380

24. Yallapu MM, Gupta BK, Jaggi M, Chauhan SC. Fabrication of curcumin encapsulated PLGA nanoparticles for improved therapeutic effects in metastatic cancer cells. J Colloid Interf Sci. 2010;351 (1):19-29. doi:10.1016/j.jcis.2010.05.022

25. Xie X, Tao Q, Zou Y, et al. PLGA nanoparticles improve the oral bioavailability of curcumin in rats: characterizations and mechanisms. J Agric Food Chem. 2011;59(17):9280-9289. doi:10.1021/jf202135j

26. Arasoglu T, Derman S, Mansuroglu B, et al. Synthesis, characterization and antibacterial activity of juglone encapsulated PLGA nanoparticles. J Appl Microbiol. 2017;123(6):1407-1419. doi:10.11 11/jam. 13601

27. Mathew A, Fukuda T, Nagaoka Y, et al. Curcumin loaded-PLGA nanoparticles conjugated with Tet-1 peptide for potential use in Alzheimer's disease. PLoS One. 2012;7(3):e32616. doi:10.1371/journal.pone.0032616

28. Kaur T, Kulanthaivel S, Thirugnanam A, Banerjee I, Pramanik K. Biological and mechanical evaluation of poly (lactic-co-glycolic acid)-based composites reinforced with 1D, 2D and 3D carbon biomaterials for bone tissue regeneration. Biomed Mater. 2017;12 (2):025012. doi:10.1088/1748-605X/aa5f76

29. Erbetta CDAC, Alves RJ, Magalh J, de Souza Freitas RF, de Sousa RG. Synthesis and characterization of poly (D, L-lactide-coglycolide) copolymer. J Biomater Nanobiotechnol. 2012;3:208-225. doi:10.4236/jbnb.2012.32027

30. Mondal J, Patra M, Panigrahi AK, Khuda-Bukhsh AR. Boldineloaded PLGA nanoparticles have improved efficiency of drug carriage and protective potential against Cisplatin-induced toxicity. J Ayurveda Integr Med. 2018;5:10-25.

31. Ravikiran T, Shilpa S, Praveen kumar N, et al. Antioxidant activity of Hemidesmus indicus (L.) R. Br. encapsulated poly (lactide-co-glycolide)(PLGA) nanoparticles. J Pharm Bio Sci. 2016;11:9-17.

32. Awah F, Eyibe U, Ikhelowa A, Anyimigbo G, Nkuche B. Protective capabilities of rutin in acute butylated hydroxytoluene-induced oxidative damage in wistar rats. Int J Pharm Front Res. 2012;2 (2):12-20.

33. Chong ZZ, Li F, Maiese K. Oxidative stress in the brain: novel cellular targets that govern survival during neurodegenerative disease. Prog Neurobiol. 2005;75(3):207-246.

34. Waris G, Ahsan H. Reactive oxygen species: role in the development of cancer and various chronic conditions. J Carcinog. 2006;5:14. doi:10.1186/1477-3163-5-14

35. Gilgun-Sherki Y, Rosenbaum Z, Melamed E, Offen D. Antioxidant therapy in acute central nervous system injury: current state. Pharmacol Rev. 2002;54(2):271-284. doi:10.1124/pr.54.2.271

36. Rhee SG. Redox signaling: hydrogen peroxide as intracellular messenger. Exp Mol Med. 1999;31(2):53-59. doi:10.1038/ emm.1999.9

37. Matsura T, Kai M, Fujii Y, Ito H, Yamada K. Hydrogen peroxide-induced apoptosis in HL-60 cells requires caspase-3 activation. Free Radic Res. 1999;30(1):73-83. doi:10.1080/ 10715769900300081 


\section{Publish your work in this journal}

The International Journal of Nanomedicine is an international, peerreviewed journal focusing on the application of nanotechnology in diagnostics, therapeutics, and drug delivery systems throughout the biomedical field. This journal is indexed on PubMed Central, MedLine, CAS, SciSearch ${ }^{\mathbb{R}}$, Current Contents ${ }^{\mathbb{R}} /$ Clinical Medicine, $^{2}$
Journal Citation Reports/Science Edition, EMBase, Scopus and the Elsevier Bibliographic databases. The manuscript management system is completely online and includes a very quick and fair peer-review system, which is all easy to use. Visit http://www.dovepress.com/ testimonials.php to read real quotes from published authors.

Submit your manuscript here: https://www.dovepress.com/international-journal-of-nanomedicine-journal 